\title{
CARTAS DE MÁRIO DE ANDRADE A CÂMARA CASCUDO: REPRESENTAÇÕES DISCURSIVAS DE AMIZADE
}

\author{
Benedita Vieira de Andrade* \\ Instituto Federal de Educação, Ciência e Tecnologia da Paraíba \\ João Pessoa, PB, Brasil
}

\begin{abstract}
Resumo: Este artigo objetiva analisar a construção de representações discursivas da relação de amizade com Câmara Cascudo em cartas que lhe enviou Mário de Andrade. Para descrever, analisar e interpretar essas representações, o texto recorre a algumas categorias semânticas provenientes da Análise Textual dos Discursos (ATD), articulando-as com outras categorias, notadamente da Lógica de Grize (1996, 1997), da Linguística Textual e da Semântica. Na fundamentação teórica, articulam-se propostas da ATD, concebidas pelo linguista Jean-Michel Adam (1999, 2008a, 2011a), da Linguística Textual (LT), da Semântica e da Lógica, enfocando, sobretudo, o fenômeno das representações discursivas. Em uma abordagem qualitativa, analisa um recorte de 10 fragmentos de 7 cartas enviadas por Mário a Cascudo. Verifica que é construído, no material analisado, um conjunto de representações discursivas para a amizade com o escritor potiguar, a partir das categorias propostas para análise e aplicadas no discurso de Mário de Andrade, destacando a representação da amizade firme e verdadeira.
\end{abstract}

Palavras-chave: Representação discursiva. Amizade. Câmara Cascudo. Mário de Andrade.

\section{INTRODUÇÃO}

Este trabalho analisa as representações discursivas da relação de amizade entre Câmara Cascudo e Mário de Andrade, fazendo um recorte de trechos de cartas de Mário de Andrade. Essas representações são construídas a partir das cartas de Mário de Andrade, que fazem parte da correspondência pessoal trocada entre os dois escritores no período de 1924 a 1944. Esses textos foram organizados por Marcos Antonio Moraes (2010) e deles construíram-se os dados analisados no presente trabalho. Trata-se de artigo de pesquisa que constitui uma amostra da tese intitulada "Representações discursivas de Câmara Cascudo por Mário de Andrade".

Luís da Câmara Cascudo e Mário de Andrade são nomes que representam muito para a história cultural do Brasil. O primeiro é considerado um dos maiores folcloristas brasileiros, uma das mais respeitáveis figuras no âmbito do folclore. Autor do Dicionário do Folclore Brasileiro, Cascudo muito contribuiu para a valorização da cultura popular no Brasil. Embora tenha se dedicado a vários outros temas, seu nome é sempre associado ao folclore. Mário de Andrade, um dos líderes e principal representante do Modernismo no Brasil, definiu as bases desse movimento, contribuindo, por meio de sua vasta obra, com as principais teses e desdobramentos dos ideais modernistas. Além de poeta,

\footnotetext{
* Doutora em Estudos da Linguagem. Coordenadora do Curso de Licenciatura em Letras a distância. Email: benedita.v@gmail.com
} 
dramaturgo, cronista e romancista, Mário foi pesquisador de folclore, gestor público na área cultural e intelectual centrado na noção de brasilidade. A importância da contribuição desses dois nomes para o cenário artístico-cultural do Brasil é inegável. É igualmente indiscutível a importância da correspondência desses dois ícones da literatura para a agenda de pesquisas não só do campo da epistolografia, mas de diferentes áreas do conhecimento. Os textos dos dois escritores representam não apenas experiências individuais, mas manifestam uma série de atividades intelectuais desenvolvidas na época em contextos sociais distintos: nordeste e sul do país. As cartas serviram à troca de informações e experimentações de linguagem. É possível afirmar que sua função mais significativa foi a didática, apresentando conceitos e instruções de forma espontânea. $\mathrm{O}$ estudo dessa correspondência permite uma visão mais ampla de seus autores e da obra que produziram. Os textos que compõem essa correspondência constituem, portanto, terreno fértil para pesquisadores ávidos de novas descobertas e oferecem amplas possibilidades de abordagem. Neste trabalho, em particular, serão analisadas as representações discursivas da amizade entre os dois escritores, construídas no discurso de Mário de Andrade.

O trabalho tem como respaldo teórico principal a Análise textual dos discursos (ATD), proposta pelo linguista francês Jean-Michel Adam, e trabalhos de estudiosos da obra desse autor. Com base nesses pressupostos teóricos, pretende-se contribuir para o campo da Linguística textual e da ATD, especialmente para os estudos da representação discursiva na área de linguística, apresentando-se um estudo que consiste na análise de textos concretos. O estudo se insere no grupo de pesquisa da ATD (UFRN) e vem contribuir para os estudos do texto, principalmente no que se refere ao nível semântico e, sobretudo, para uma melhor compreensão da noção de Representação Discursiva (Rd), já que abrange a construção de representações discursivas de Luís da Câmara Cascudo (LCC) por Mário de Andrade (MA) por meio de algumas categorias semânticas propostas pela ATD. O objetivo é, portanto, analisar e descrever como a relação entre essas categorias promove a composição de significações (entendemos que as abordagens que tratam do significado do ponto de vista representacional e do ponto de vista referencial são complementares) e contribui para construir as representações discursivas.

No campo da Linguística Textual, só há bem pouco tempo (acreditamos que há menos de uma década), têm despontado trabalhos que investigam o tema da Rd. Nosso objeto de estudo é, portanto, ainda pouco explorado, sobretudo no âmbito da ATD, em que só recentemente têm sido desenvolvidas pesquisas voltadas especificamente para esse campo do conhecimento. Dessa forma, para aplicarmos categorias de análise apropriadas ao estudo das representações discursivas, recorremos a um conjunto de disciplinas teóricas, como Linguística Textual, Análise do Discurso e Semântica. Assim, buscamos no âmbito dessas disciplinas, e adaptamos conforme nossos propósitos de pesquisas, categorias como expressões referenciais, predicação, modificação e conexão. Essa conjunção de categorias de análise vem preencher a lacuna existente no estudo das Rd, no que concerne à abordagem apresentada neste trabalho e, ainda, contribuir com uma metodologia inovadora no tratamento do tema. Dessa forma, um dos aspectos inovadores deste trabalho é o estudo da representação discursiva no âmbito da Linguística Textual. Assim, entendemos ser relevante o estudo da Rd, na perspectiva da ATD, para a agenda de estudo desse campo da Linguística. 
A noção de representação discursiva ( $R d$ ) aqui utilizada é apreendida, especialmente, da obra de Adam (1999, 2008a, 2011a) e autores que o seguem, como também de Grize (1997). De forma simplificada, a representação discursiva seria a "imagem" do locutor, do auditório, ou do tema tratado proposta pelo discurso. Sempre que se enuncia ou se lê uma proposição está-se construindo uma representação discursiva. Essa $\mathrm{Rd}$ que se constrói é suscetível de ser confirmada ou invalidada, modificada ou complementada por outras proposições. Com efeito, as Rd não são dadas, mas construídas a partir da realidade apresentada pelo texto. É o texto que propõe o sentido e este pode ser descrito como uma imagem mental que o receptor constrói da realidade tal qual esta lhe é oferecida pelo texto. Assim, o texto é uma proposição de sentido que o interpretante é convidado a (re)construir. O sentido de um enunciado é inseparável dessa atividade de reconstrução. O sentido de um enunciado (o dito) é inseparável de um dizer, isto é, de uma atividade enunciativa significante que o texto convida a (re)construir. É nessa perspectiva que abordamos as representações discursivas: toda Rd é, semanticamente, construída pelo interpretante a partir do texto, dos enunciados e em função de suas próprias finalidades (objetivos, intenções) e de suas representações psicossociais da situação, do enunciador e do mundo do texto, assim como de seus pressupostos culturais (cf. ADAM, 2008a [2011a]).

Para analisar as representações discursivas da relação de amizade com Câmara Cascudo no discurso de Mário de Andrade, adotamos algumas categorias semânticas propostas por Passeggi (2001), com base na lógica natural de Grize. Essas categorias são rearticuladas com categorias da ATD propostas por Adam (2008a; 2008b; 2011a). Dessa forma, retemos cinco categorias semânticas principais para a análise das representações discursivas da amizade com Luís da Câmara Cascudo no discurso de Mário de Andrade: referenciação (que restringimos a expressões referenciais), modificação (aspectualização), predicação, relação e conexão. No curso da análise, essas categorias se articulam para compor os efeitos de sentido. Na sequência, faremos uma breve descrição de cada uma dessas categorias.

De acordo com Cavalcante (2012), as expressões referenciais são recursos linguísticos que permitem nomear os objetos de discurso elaborados durante o evento de comunicação. São expressões utilizadas para fazer remissão a esses objetos. O processo de referenciação diz respeito à atividade de construção de referentes (ou objetos de discurso) depreendidos por meio de expressões linguísticas específicas para tal fim, chamadas de expressões referenciais. Quanto ao referente, é um objeto, uma entidade, uma representação construída a partir do texto e percebida, na maioria das vezes, a partir do uso de expressões referenciais.

A operação de aspectualização é a mais comumente admitida como base da descrição. Apoiada na tematização (ver referenciação), essa macro-operação associa um conjunto de operações que se combinam frequentemente e consiste na seleção das partes e na qualificação do todo ou das partes do objeto da descrição. A partição é a seleção das 
partes do objeto da descrição. A análise de partes e subpartes de um todo tende a fragmentar o objeto de discurso. Já a qualificação, ou atribuição de propriedades, evidencia propriedades do todo e/ou das partes selecionadas pela operação de fragmentação. Essa operação se realiza, na maioria das vezes, pela estrutura do grupo nominal nome + adjetivo e pelo recurso predicativo ao verbo ser. Também "consiste, frequentemente, de uma relação predicativa do tipo ter que realiza a operação de partição, quase sempre com uma qualificação vinculada" (ADAM, 2011a, p. 221). Para evitar possíveis equívocos conceituais desse termo com um outro termo, o de "aspecto verbal", bastante usado na nomenclatura gramatical do português, decidimos optar pelo uso do termo "modificação", conforme empregado por Chierchia (2003). A modificação proposta por esse autor corresponde à categoria aspectualização de Adam e atende satisfatoriamente a nossos propósitos neste trabalho.

A predicação será entendida, em harmonia com Passeggi et al. (2010), como seleção dos processos, ou seja, a predicação (verbal) remete tanto à operação de seleção dos predicados como ao estabelecimento da relação predicativa no enunciado. Assim, a predicação designa os processos, no sentido amplo: ações, estado, mudança de estado.

A conexão é uma operação que assegura o agrupamento das proposiçõesenunciado. Essas proposições se organizam em períodos, que compõem as sequências. $O$ período é, conforme Adam (2008a), uma unidade textual que articula proposições e sequências e resulta das mais variadas formas de ligações, incluindo as ligações por conexão, que são asseguradas por conectores. Assim, um período pode corresponder a várias proposições, ligadas pelo critério de conexão. Para Adam (2008a; 2011a; 2011b), essa macro-operação agrupa duas outras relações: relação de contiguidade e relação de analogia. A primeira corresponde a uma relação espaçotemporal do objeto de discurso. A segunda é uma forma de assimilação comparativa ou metafórica que permite descrever o todo ou as partes, colocando-os em relação com outros objetos de discurso.

Em sua proposta, Rodrigues et al. (2010) redefinem as categorias da ATD, articulando-as com operações lógico-discursivas de Grize (1997). Assim, os autores retêm, dentro dessa operação, apenas a relação de analogia. As circunstâncias espaçotemporais são analisadas na operação de Localização. Seguindo esse posicionamento, vamos analisar, por meio dessa categoria, relações de analogia, comparação e metáfora. Empregaremos essa operação em conformidade com a proposta de Adam apenas no que o autor considera como analogia, ou seja, associação com outros elementos, geralmente por comparações ou metáforas.

Convém destacar que o funcionamento das representações discursivas que propomos analisar será observado na interação, em contextos de uso situados, nas atividades dos interlocutores. Para tanto, propomos observar também o que o escritor dos textos analisados faz e como age para construir representações do mundo em sistema de coprodução discursiva. Não pretendemos tomar essas formas como categorias fixas, dadas a priori, mas observá-las como construtos, formas que são construídas na dinâmica das interações. 


\subsection{PROCEDIMENTOS DE ANÁLISE}

Para este trabalho, foram utilizados 10 fragmentos selecionados de 7 cartas de Mário de Andrade enviadas a Câmara Cascudo durante os vinte anos de correspondência entre os dois interlocutores. Os fragmentos analisados focalizam representações discursivas da relação de amizade entre os escritores, evidenciadas nas cartas do escritor paulista. Cada fragmento recebeu uma codificação que identifica o texto em que figura e sua sequência dentro do respectivo texto. Dessa forma, se foram selecionados dois fragmentos do texto 1, por exemplo, esses fragmentos receberam a codificação (1MA1) e (1MA2). O primeiro algarismo identifica o texto (essa numeração obedece à ordem cronológica dos textos da correspondência), seguido da sigla do seu autor, e o segundo identifica o fragmento analisado. Essa numeração não corresponde à numeração dos textos no original; ela foi definida especificamente para este trabalho. A análise não segue a ordem cronológica dos textos, posto que se organiza por eixos temáticos. Dessa forma, é possível um texto codificado com numeração sequencial maior preceder um outro de numeração inferior.

As representações discursivas da amizade entre MA e LCC no discurso de Mário organizaram-se com base em três eixos temáticos, rotulados como a camaradagem, a confiança e ofortalecimento dos laços. A análise focaliza cada fragmento, em separado ou em conjunto, conforme estejam no mesmo eixo isotópico. Após a análise interpretativa dos fragmentos com base nas categorias propostas, será apresentada uma síntese das análises que interpreta essas categorias, descrevendo como a relação entre elas compõe significações e contribui para a construção das representações discursivas focalizadas.

\subsection{ANÁLISE DE ALGUNS FRAGMENTOS}

Apresentaremos a análise de alguns fragmentos que evidenciam as representações construídas no discurso de MA para a relação de amizade entre ele e o nordestino. Desses fragmentos podem-se inferir representações como a camaradagem, a confiança mútua, a amizade firme, verdadeira e desinteressada. Para mais clareza e objetividade na apresentação dos dados, esses fragmentos serão agrupados por temáticas recorrentes, organizadas em dois eixos temáticos.

\subsubsection{A CAMARADAGEM}

(1MA1) Luís, eu sou tão feliz! Puxa! Que camaradão amigo mesmo de verdade eu arranjei em você.

(5MA1) Mais e muito mais você tem, não o direito, mas o dever de exigir de mim, por tudo quanto já tem sido nossa perfeita camaradagem que cada vez mais se estreita. Duma atração mútua para camaradagem pouco distou. Depois insensivelmente de camaradagem pra cordialíssimo prazer de dois seres juntos passamos insensivelmente. E insensivelmente fomos passando disso pra essa coisa mais magnífica e rara em que a palavra amigo não tem mais o sentido quotidiano em que todos a empregamos mas já vem de raízes inamovíveis. 
Nos fragmentos (1MA1) e (5MA1), as representações para o referente LCC e a relação de amizade entre este e o enunciador são designadas, sobretudo, pelas expressões "camaradão amigo mesmo de verdade" e "camaradagem". Essas expressões sinalizam o grau de amizade entre os dois interlocutores e o fortalecimento dessa relação, que ia se tornando cada vez mais sólida. Os organizadores textuais "Depois" e "E" em (5MA1), além de marcar a conexão entre as unidades semânticas (proposições e períodos), são empregados para ordenar as partes da representação discursiva no eixo do tempo, indicando a continuidade da relação de amizade. Embora com a função principal de adição, esses organizadores temporais promovem, no discurso, a progressão textual e sinalizam a evolução da amizade. O fragmento (1MA1) destaca, sobretudo por meio das expressões exclamativas, o entusiasmo do enunciador com a amizade do natalense, o que é representado pela expressão referencial "camaradão", que adquire valor afetivo de intensidade. Essa designação é reforçada pelos modalizadores "amigo mesmo de verdade", numa manobra do enunciador para conferir maior credibilidade a suas afirmações. A escolha de propriedades positivas, modalizadas pelo tom exclamativo, reforça a intenção do locutor de revelar para o interlocutor o seu estado de espírito, a satisfação em tê-lo como amigo.

Em (5MA1), como já foi assinalado, a continuidade e progressão da amizade são sinalizadas por meio dos conectores que marcam a evolução da relação de "camaradagem" para "prazer de estar juntos" e daí para algo "mais magnífico e raro". Esses conectores permitem a retomada de referentes para novas designações e, juntamente com o conector argumentativo mas (contra-argumentativo marcador de um argumento forte), acrescentam a orientação argumentativa do enunciado. Portanto, a representação da amizade em (5MA1) é construída, sobretudo, por meio da conexão.

\begin{abstract}
(6MA2) O retrato, você é retratista bom, está muitíssimo parecido e ponhamos que regularmente favorecido, o que vai em conta, não da amizade, o que era insulto, mas em conta da perfeita compreensão que entre nós existe, e que de dois literatos que se escrevinhavam cartas, acabou fazendo esta amizade de hoje, mais que admirável, verdadeiramente necessária para mim.
\end{abstract}

A estrutura de (6MA2) estabelece uma relação de causalidade entre o "retrato" delineado por LCC sobre o amigo paulista e a relação de amizade entre os dois. Para MA o retrato feito pelo amigo estava favorecido pela amizade. Os índices de avaliação "perfeita compreensão", "amizade mais que admirável", "verdadeiramente necessária" manifestam a perspectiva de MA sobre a sua amizade com o potiguar. Para o paulista, a amizade, além de se constituir como perfeita compreensão, já era algo necessário para ele. O operador "mas”, empregado para assinalar a retificação, refuta a voz do possível opositor de que o retrato estaria favorecido pela amizade - opinião invalidada e desqualificada pelo enunciador, que se antecipa em dizer que seria insulto - e introduz o argumento forte, prevalente. Dessa forma, as duas proposições de (6MA2) em relação de oposição são assumidas por enunciadores diferentes: o locutor e o interlocutor. $\mathrm{O}$ imperfeito ("era") foi empregado no lugar de "seria" para predicar a hipótese, a suposição. A amizade entre os dois era mais que admirável, era necessária para MA. Essa asserção é feita de forma enfática, engajando o enunciador com o emprego do modalizador "verdadeiramente", que confere credibilidade ao que é afirmado. 
(3MA2) Os outros são paulistas, são daqui mesmo e você é brasileiro; e de tão longe um dia me ofereceu mão tão apertando que me deu confiança verdadeira.

(6MA1) Eu carecia assim de alguém, de alguém que me estimasse, me quisesse muito bem, mas não fosse dessa terrível piedade dos ditirambos elogiásticos sem nexo, que me fizesse um minuto o exame de consciência de mim. Eu mesmo era impossível.

Em (3MA2), pode-se construir a Rd da amizade pela operação de localização espacial e temporal. O localizador espacial "tão longe" situa o referente da descrição no espaço físico, espaço considerado distante pelo enunciador. O localizador temporal "um dia" situa a descrição no tempo, num tempo longínquo, que remonta, talvez, às primeiras frases trocadas entre os dois amigos. Um dia, num tempo pretérito, LCC estendeu a mão a MA, num aperto de mão apertado, o que lhe deu confiança verdadeira. Vale destacar que esse aperto de mão mencionado por Mário ainda não havia acontecido no plano real, visto que a primeira passagem de Mário por Natal só aconteceria em agosto de 1927, ocasião em que os dois amigos se encontram pela primeira vez (cf. MORAES, 2010). O gesto descrito por MA pode ser situado num plano metafórico, simbolizando a troca de cordialidade por meio das cartas.

Para atribuir sentido ao enunciado de (3MA2), faz-se oportuno associar o que MA descreve como "oferecer a mão" com o gesto de apertar a mão, um cumprimento que expressa sentimento positivo de amizade, afinidade ou confiança entre duas pessoas. Pode-se construir, para "oferecer a mão", o sentido de oferecer amizade, confiabilidade. A confiança veio pelo gesto do amigo oferecendo amizade, pela nacionalidade, pela distância, pela afinidade e admiração mútua. Tudo isso levou o escritor paulista a declarar ao amigo potiguar confiança verdadeira. A escolha da expressão referencial "confiança verdadeira" imprime a essa declaração a força da asserção. O modalizador "verdadeira" verbaliza uma avaliação do enunciador sobre o conteúdo do substantivo "confiança", predicando o sentido desse substantivo de forma subjetiva. Ao empregar a expressão "confiança verdadeira" MA propicia espaço para atribuir ao referente "confiança" novas propriedades, obtidas com o emprego do modalizador epistêmico asseverativo "verdadeira".

Em (6MA1), pode-se inferir das imagens propostas pelo discurso de MA a representação que ele constrói para LCC: o amigo leal e sincero em quem podia confiar. As categorias que concorrem para construir essa Rd são a conexão e, principalmente, a predicação. A predicação se realiza, sobretudo, com as formas subjuntivas dos verbos estimar, querer, fazer e ser, que indicam ação-processo, nas três primeiras formas, e estado na última forma. Essas formas expressam, na sua modalidade (imperfeito do subjuntivo), anterioridade em relação ao tempo da enunciação. A forma verbal "carecia", que inicia o período, indica anterioridade pontual e remete a um estado de coisas durativo: a necessidade de ter um amigo sincero, alguém como LCC, era anterior ao momento da enunciação e se prolongava no tempo. Nesse contexto, o imperfeito também adquire valor de pressuposição; tem a propriedade de pressupor algo que acontecia e não acontece mais, uma mudança de estado (carecia, mas não carece mais). Dessa forma, pode-se interpretar que MA encontrou em LCC o amigo de que precisava e agora essa necessidade está satisfeita, configurando a mudança de estado. 
As formas do imperfeito do subjuntivo: estimasse, quisesse, fosse e fizesse também expressam uma anterioridade problemática (Cf. CASTILHO, 2010), e um estado de coisas conjectural. MA declara que, em LCC, encontrou o amigo fiel, o "alguém" de quem carecia para lhe fazer "um exame de consciência", já que ele próprio seria impossível. Essas predicações: estimasse, quisesse e fosse constroem a Rd do amigo leal que, por estimar o outro e lhe querer bem, não lhe faria falsos elogios. Para descrever o tipo de amigo que desejava e que encontra em LCC, MA emprega uma série de relativas predicativas: "que me estimasse, [que] me quisesse muito bem [...] que me fizesse um minuto [...]". Essas relativas introduzem novas predicações no imperfeito do subjuntivo e funcionam como qualificantes, posto que indicam exatamente o tipo de amigo a que MA se referia: alguém que tivesse essas características.

A conexão dessas representações ocorre por meio do conector contraargumentativo "mas", que opera a relação de oposição entre o amigo ideal, o amigo que MA desejava, e o que ele rejeitava: a "piedade dos ditirambos elogiásticos". Infere-se dessas imagens que MA já não apreciava as palavras lisonjeiras e os elogios tendenciosos. Daí referir-se à "terrível piedade dos ditirambos elogiásticos", numa postura cética e de repúdio aos elogios entusiásticos que não correspondiam à realidade. $\mathrm{O}$ conector "mas" vem destacar essa Rd da sinceridade e fidelidade das palavras de LCC construídas no discurso de MA. O emprego do "mas" cria um julgamento implícito das amizades que o enunciador estava acostumado a presenciar.

\begin{abstract}
(2MA1) Gui é muito leviano mesmo, tem dessas e creio mesmo que por causa dessa leviandade nunca chegamos a uma amizade largada que nem a que tenho com você com o Osvaldo com o Manuel Bandeira e com o Drummond de Minas.
\end{abstract}

(7MA1) Você ter me vindo pedir qualquer serviço pra ganhar me doeu completamente porque sei você não fazia isso se não estivesse em forte apuro. Você foi sempre, dentre os amigos que tenho por aí tudo, um dos que, não sendo ricos, nunca me pediram coisa nenhuma.

Em (2MA1) MA admite que nunca conseguira ter uma amizade verdadeira com Guilherme de Almeida, e atribui isso à leviandade desse escritor. Essa informação serve como ponto de partida para o enunciador confirmar, por meio da comparação, a "amizade largada" com o natalense. As operações de relação (comparação) e conexão (relação de causalidade) embasam o fragmento, construindo a representação da amizade entre MA e LCC: uma amizade autêntica, espontânea. Essa amizade espontânea e desinteressada também é retratada em (7MA1), em que se pode apreender, do discurso do enunciador, que a relação de amizade entre o nordestino e o paulista não se pautava em interesses pessoais ou troca de favores. Assim, o pedido de ajuda do nordestino causa preocupação em MA, levando-o a deduzir que o amigo se encontrava em forte apuro. $\mathrm{O}$ enunciador justifica a preocupação, por meio do conector porque, declarando que o natalense nunca lhe pedira coisa alguma. Há ainda no fragmento uma implícita relação de oposição por concessão, que põe em destaque o fato de LCC nunca ter pedido "coisa nenhuma" ao amigo, o que se opõe à condição de não ser rico. A informação que fica subentendida aponta para a hipótese de que, não sendo rico, seria natural que LCC pedisse favor ao amigo paulista. A operação que constrói a representação de amizade nesse fragmento é, sobretudo, a conexão. 
(3MA1) Espero em Deus que hei de ter vida e forças pra te dar coisas mais valiosas e guardar o nome forte da nossa amizade em qualquer coisa de vida maior.

(4MA1) A ideia de ficar compadre de você, crismando o Fernando Luís, me iluminou. [...] E me é doce ver como os passos da vida vão se fechando em torno de nós, a amizade vai se cerrando, os laços se amarrando e a gente pode nessas redes firmes sossegar um bocado do que vai lá fora.

Em (3MA1), a representação da amizade é construída, sobretudo, por modificação, a qual permite selecionar atributos para caracterizar essa relação, de modo que é possível se ter uma ideia do que o locutor considera relevante ou irrelevante. Assim, depreende-se que, no entendimento de MA, para uma amizade tão firme, a dedicatória ao amigo deveria ser de obra grandiosa, de maior valor do que as que vinha apresentando. Dessa forma, dedicando ao amigo obra de maior valor, estaria guardando o nome da amizade em algo mais sólido e duradouro. Provavelmente as "coisas mais valiosas" a que o poeta se refere diz respeito a uma grande obra, criação que imortalizasse seu nome e, por conseguinte, mantivesse guardado o nome da amizade com o potiguar em algo de vida maior, ou seja, algo mais memorável. Observe-se que o locutor estabelece uma relação de causalidade entre os dois fatos: ofertar ao amigo "coisa mais valiosa" e guardar o nome da amizade em "coisa de vida maior". Essa relação é realizada com o emprego do conector "e", que adquire no texto valor consecutivo. A escolha do substantivo "coisas" para nomear o referente, que é retomado por "coisa", sinaliza a intenção do locutor de não limitar-se a falar, por exemplo, de livro, obra, mas de algo mais abstrato, que poderia compreender uma série de trabalhos ou produções literárias de natureza diversa. "Coisa" é algo inominável, abstrato e pode se referir a qualquer realização.

Em (4MA1), a Rd da relação de amizade entre MA e LCC é construída pela operação de conexão, sobretudo pela associação semântica entre as palavras. Esse procedimento constitui a coesão lexical do texto, abrangendo as relações de significado que são criadas entre unidades lexicais, como substantivos e verbos, motivando uma aproximação semântica entre tais unidades. Há, assim, uma convergência das palavras quanto ao sentido que expressam, de forma que "passos da vida", "amizade" e "laços" se associam e entram em correlação com as formas gerundivas "fechando", "cerrando", "amarrando". Observe-se que essas formas compõem o quadro de referência que constrói o cenário do texto, ancorado na analogia com o laço que se amarra, o que representa o vínculo afetivo, a relação de amizade que se firma. Para retomar todas essas ações, o enunciador emprega o termo "redes firmes", fazendo um sumário de todo o período precedente. Essa expressão nominal substitui toda a predicação precedente e ainda a recategoriza: todos os laços são rotulados como "redes firmes", expressando a solidificação do relacionamento. Para MA, a solidez da amizade se concretizaria pela relação de compadrio com o amigo natalense. Essa relação, retomada pela qualificação sintética "redes firmes", representava para Mário um apoio emocional.

Convém chamar a atenção também, no enunciado de (4MA1), para as metáforas empregadas por Mário para descrever a relação de amizade entre ele e LCC. Essas construções se ancoram na relação imagética simbolizada pelo emprego metafórico de palavras e expressões, como "passos da vida", "laços" e "redes". Todas as metáforas do fragmento remetem à ideia de intimidade. A primeira, "os passos da vida vão se 
fechando", pode ser interpretada numa perspectiva de proximidade de interesses. A segunda, "a amizade vai se cerrando", e a terceira, "os laços se amarrando", remetem a uma maior intimidade. A última metáfora repousa na ideia de afinidade e confiança mútua.

\begin{abstract}
(1MA2) Na nossa amizade Luís, me parece que já passamos do tempo do aperto de mão e do "você" apenas... Já estamos no período mais amigo em que a gente pode passar dez minutos um ao lado do outro, sem falar, sem procurar assunto, vivendo apenas a vida uma só de dois iguais e bem se conhecendo.
\end{abstract}

Em (1MA2), MA destaca a intensificação da intimidade entre ele e o interlocutor. A passagem de uma fase mais formal para uma relação mais intensa e espontânea, em que se podem abandonar as formalidades e se entregar a uma amizade mais natural, despretensiosa. A categoria mais expressiva para construir a representação da relação de amizade nesse fragmento é a localização temporal. As expressões temporais "do tempo", "no período", "dez minutos" delimitam circunstâncias de tempo, mas não um tempo cronológico, mensurável, remetem a um tempo vago, metafórico e fictício. Esse tempo, provavelmente, estaria mais marcado pela intensidade da amizade do que pelo próprio decorrer dos dias, já que se trata de carta escrita no segundo ano da correspondência. $O$ que o autor da carta quer destacar é a fase a que convergira a amizade: a fase da confiança e da mútua compreensão. O estado de coisas que é descrito debuxa a espontaneidade da relação entre os dois escritores, ou pelo menos a manifestação do desejo escritor paulista em relação ao seu alter ego.

\title{
3.3 SÍNTESE INTERPRETATIVA DOS RESULTADOS DA RD DA RELAÇÃO DE AMIZADE ENTRE MA E LCC NO DISCURSO DE MARIO
}

Neste item será apresentada a síntese das representações discursivas da relação de amizade entre LCC e MA no discurso de Mário, construídas pelas categorias semânticas: referenciação, modificação (modificadores dos referentes e da predicação), predicação, conexão, relação e localização espaçotemporal. Algumas expressões, como "camaradagem" e "laços" referenciam a relação de amizade entre os dois escritores, assim também as propriedades atribuídas a essa relação, como a "perfeita camaradagem", e a "confiança verdadeira". Além dessas categorias, os processos verbais, os conectores e as expressões circunstanciais de tempo e espaço também contribuem para construir essas representações.

Expressões referenciais como amizade, confiança, camaradagem e compreensão constroem, a partir dos textos de MA, as representações da relação de amizade entre LCC e MA. Essas representações são depreendidas por meio das expressões linguísticas, que são introduzidas nos textos, sobretudo, por descrição definida. Essas expressões linguísticas, juntamente com os modificadores, constroem as representações discursivas analisadas neste trabalho. Apenas em duas ocorrências, esses objetos são introduzidos por anáforas demonstrativas. Essas expressões recebem, por meio dos modificadores, propriedades que se evidenciam pela estrutura nome + adjetivo, nome + locução adjetiva e adjetivo + nome. 
Quanto aos verbos e locuções verbais empregados, observa-se maior ocorrência daqueles que indicam ação, ou seja, são verbos e locuções que apresentam em sua estrutura um agente na função de sujeito. Além dos verbos de ação, observa-se, também, ocorrência significativa de verbos que indicam estado, aqueles cuja estrutura apresenta um agente na função de sujeito, que não é causativo nem afetado, é neutro. Quanto aos modificadores desses verbos, destacam-se aqueles que apresentam valores circunstanciais de intensidade, modo e negação.

Quanto à conexão, os conectores mais frequentes são os organizadores textuais, especialmente o conector "E", que ocorre em maior frequência com valor de simples adição (enumeração), seguido pelo "E" com valor sequencial. O conector contraargumentativo "mas", que introduz um argumento forte em suas três ocorrências, em (5MA1) e (6MA1), tem valor refutativo e, em (6MA2), apresenta valor de retificação. O conector argumentativo "porque", com a função de marcar os argumentos, assinala a justificativa em (7MA1), e o conector "se" tem valor condicional.

Quanto à categoria localização, destacam-se as expressões circunstanciais espaçotemporais, que situam os objetos de discurso no espaço e no tempo da enunciação, observando-se, quanto ao tempo, que os objetos se situam no passado ou no presente em relação ao tempo da enunciação. Para a localização espacial, destacam-se os espaços "tão longe", que remete à terra natal de LCC, ou seja, o Rio Grande do Norte; "por aí" e "lá fora" que indicam localização imprecisa.

A categoria mais expressiva para construir as representações discursivas nesta análise é, notadamente, a referenciação. A seleção lexical constrói a isotopia no eixo da amizade. Nesse eixo, expressões referenciais como "amigo", "camaradão", "amizade", "camaradagem", "laços", "passos", "redes", "compreensão" manifestam referentes que remetem à relação de amizade entre os dois interlocutores e adquirem nos textos analisados significados particulares. O referente construído para LCC é designado pelos termos "amigo" e "camaradão". As expressões "amizade", "camaradagem", "laços", "passos", "redes", "compreensão" nomeiam a relação de amizade entre os dois intelectuais. A esses referentes são atribuídos traços semânticos que vêm complementar a representação dessa relação. Assim, expressões como "amigo de verdade", "amizade largada, admirável e necessária”, "perfeita camaradagem”, "confiança verdadeira", "atração mútua", "perfeita compreensão" são termos que representam a relação de amizade entre os dois escritores, na ótica do escritor paulista.

A predicação e seus modificadores circunstanciais também se revelam consideravelmente relevantes na construção da Rd da amizade com LCC nesses fragmentos. Alguns verbos sinalizam o fortalecimento da relação de amizade, que evolui de atração mútua para camaradagem, depois para o prazer de estar juntos, e culmina em alguma "coisa mais magnífica e rara em que a palavra amigo não tem mais o sentido quotidiano em que todos a empregamos mas já vem de raízes inamovíveis". E essa evolução, na concepção de MA, foi se dando aos poucos, insensivelmente. A camaradagem se estreitou até atingir a confiança verdadeira em que se pode sossegar. Essa representação se completa com os elementos que localizam a amizade no tempo, revelando sua evolução, e com os elementos que fazem a conexão entre as proposições, dentre os quais se destaca o conector "E". 


\section{CONSIDERAÇÕES FINAIS}

O estudo focalizou as Rd da relação de amizade entre LCC e MA construídas no discurso de Mário de Andrade por meio de algumas categorias semânticas. A análise permite construir para essa relação de amizade, por meio dessas categorias, traços como camaradagem, confiança, compreensão. Essas representações são inferidas por meio dos recursos linguísticos (escolhas lexicais, como expressões referenciais, modificadores, verbos, conectivos, expressões circunstanciais) a que MA recorre para representar a amizade entre ele e LCC. Esses recursos possibilitam a (re)construção das imagens da amizade, construídas discursivamente, proporcionando uma multiplicidade de representações dessa relação ao longo dos vinte anos de correspondência entre os dois escritores.

O conjunto de categorias que adotamos para alcançar nosso objetivo nos permitiu interpretar as várias representações construídas no discurso de MA para a amizade entre ele e o escritor potiguar e descrever os efeitos de sentido que são produzidos pela relação dessas categorias. Com esse propósito, nossa análise focalizou o texto numa perspectiva semântico-discursiva que permitiu investigar, por meio das propriedades suscitadas pelas categorias empregadas, o fenômeno da representação discursiva construída no texto com base nas imagens que foram emergindo da interpretação. Isso vem ratificar a afirmação de Adam (2008a [2011a]) de que o texto propõe o sentido e o interpretante constrói a Rd a partir dos seus enunciados.

Para realizar o estudo das Rd da relação de amizade entre Câmara Cascudo e Mário de Andrade no discurso do escritor paulista, desenvolvemos uma temática inovadora, num estudo inédito. De fato, muitos estudos já foram feitos desses documentos, mas nenhum procurou traçar uma imagem de LCC a partir deles, tampouco da sua amizade com o escritor de Macunaíma. E nisso inovamos. Acreditamos, portanto, que nosso trabalho pode contribuir para aprofundar os estudos sobre o texto, investigando a respeito das suas várias particularidades, sobretudo na sua dimensão semântica. O trabalho vem trazer também uma contribuição cultural para o Estado do Rio Grande do Norte e - por que não dizer? - para o Brasil, ao nos proporcionar um maior conhecimento deste importante autor potiguar.

\section{REFERÊNCIAS}

ADAM, J.-M. Entre énoncé et énonciation: la schématisation. In: Linguistique textuelle: des genres de discours aux textes. Paris: Nathan, 1999. Cap. 4: p. 101-118. A linguística textual: introdução à análise textual dos discursos. São Paulo: Cortez, 2008a. Imagens de si e esquematização do orador: Pétain e De Gaulle em junho de 1940. In: AMOSSY, R. (Org.). Imagens de si no discurso: a construção do ethos. São Paulo: Contexto, 2008b. "Viva o Québec livre": análise textual de um discurso do general de Gaulle. In: RODRIGUES, M. G. S; SILVA NETO, J. G; PASSEGGI, L. (Org.). Análises textuais e discursivas: metodologia e aplicação. São Paulo: Cortez, 2010. p. 95-126. . A Linguística textual: introdução à análise textual dos discursos. 2. ed. rev. e aum. São Paulo: Cortez, 2011a. Les textes: types et prototypes. 3. ed. rev. e aum. Paris: Armand Colin, $2011 \mathrm{~b}$. CAVALCANTE, M. M. Os sentidos do texto. São Paulo: Contexto, 2012. CHIERCHIA, G. Semântica. Trad. Luiz Arthur Pagani, Lígia Negri, Rodolfo Ilari. Campinas, SP: Editora da Unicamp; Londrina, PR: Eduel, 2003.

GRIZE, J.-B. Logique naturelle et communications. Paris: PUF, 1996. Logique et language. Paris: Ophrys, 1997. 
MORAES, M. A. (Org.). Câmara Cascudo e Mário de Andrade. Cartas, 1924-1944. São Paulo: Global, 2010.

PASSEGGI, L. A estruturação sintático-semântica dos conteúdos discursivos: categorias discursivas da lógica natural para a linguística. In: ; OLIVEIRA, M. S. (Org.) Linguística e Educação. São Paulo: Terceira Margem, 2001. p. 245-269.

PASSEGGI, L. et al. A análise textual dos discursos: para uma teoria da produção co(n)textual de sentido. In: BENTES, A. C; LEITE, M. Q. Linguística de texto e análise da conversação: panorama das pesquisas no Brasil. São Paulo: Cortez, 2010. p. 262-312.

RODRIGUES, M. G. S; SILVA NETO, J. G.; PASSEGGI, L. "Voltarei. O povo me absolverá...”: a construção de um discurso político de renúncia. In: ; SILVA NETO, J. G; PASSEGGI, L. (Org.) Análises textuais e discursivas: metodologia e aplicação. São Paulo: Cortez, 2010.

RODRIGUES, M. G. S; SILVA NETO, J. G.; PASSEGGI, L. (Org.). Análises textuais e discursivas: metodologia e aplicação. São Paulo: Cortez, 2010.

Recebido em: 16/01/17. Aprovado em: 10/01/18.

Title: Letters from Mário de Andrade to Câmara Cascudo: discursive representations of friendship

Author: Benedita Vieira de Andrade

Abstract: This article aims to analyze the construction of discursive representations friendship relationship with Câmara Cascudo in letters sent by Mário de Andrade. In order to describe, analyze and interpret these representations, the text recurs to some semantic categories from the Discourse Textual Analysis (DTA) by articulating them with other categories, notably Grize's Logic (1996,1997), Text Linguistics and Semantics. In the theoretical foundation, proposals of Textual Analysis of Discourses are articulated, conceived by the linguist Jean-Michel Adam (1990, 2008a, 2011a), Text Linguistics, Semantics and Logic, focusing especially on the phenomenon of discursive representations. Through a qualitative approach, an analysis is made at 10 fragments of 7 letters written by Mário de Andrade and sent to Câmara Cascudo. Therefore, in the corpus analyzed, a set of discursive representations is constructed from the friendship with the potiguar writer, through categories proposed for analysis and used in Mário de Andrade's discourse, highlighting the representation of a solid and truly friendship.

Keywords: Discursive Representation. Friendship. Câmara Cascudo. Mário de Andrade.

Título: Cartas de Mário De Andrade a Câmara Cascudo: Representaciones discursivas de amistad

\begin{abstract}
Autora: Benedita Vieira de Andrade
Resumen: Este artículo tiene el objetivo de analizar la construcción de representaciones discursivas de relación de amistad con Câmara Cascudo en cartas que se le envió Mário de Andrade. Para describir, analizar e interpretar esas representaciones, el texto recurre a algunas categorías semánticas provenientes del Análisis Textual de los Discursos (ATD), articulándolas con otras categorías, especialmente de la Lógica de Grize (1996, 1997), de la Lingüística Textual y de la Semántica. En la fundamentación teórica, se articulan propuestas de la ATD, concebidas por el lingüista Jean-Michel Adam (1999, 2008a, 2011a), de la Lingüística Textual (LT), da Semántica y de la Lógica, enfocando, sobretodo, el fenómeno de las representaciones discursivas. En un abordaje cualitativo, se analiza un recorte de 10 fragmentos de 7 cartas enviadas por Mário a Cascudo. Se verifica que es construido, en el material analizado, un conjunto de representaciones discursivas para la amistad con el escritor potiguar, desde de las categorías propuestas para análisis y aplicadas en el discurso de Mário de Andrade, despegándose la representación de la amistad firme y verdadera.
\end{abstract}

Palabras clave: Representación discursiva. Amistad. Câmara Cascudo. Mário de Andrade.

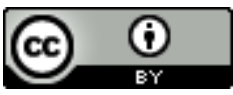

Este texto está licenciado com uma Licença Creative Commons Atribuição 4.0 Internacional 